\title{
Article \\ Effectiveness Improvement in Manufacturing Industry; Trilogy Study and Open Innovation Dynamics
}

\author{
Ashwani Tayal ${ }^{1}\left(\mathbb{D}\right.$, Nirmal Singh Kalsi ${ }^{2}$, Munish Kumar Gupta ${ }^{3,4}{ }^{(D}$, Danil Yurievich Pimenov ${ }^{4}$ (D), \\ Murat Sarikaya ${ }^{5}$ (D) and Catalin I. Pruncu $6,7, *$ (D)
}

1 Department of Mechanical Engineering, I.K. Gujral Punjab Technical University, Jalandhar 144603, India; ashwanitayal01@gmail.com

2 Department of Mechanical Engineering, Beant College of Engineering \&Technology, Punjab 143521, India; ns_kalsi@yahoo.com

3 Key Laboratory of High Efficiency and Clean Mechanical Manufacture, Ministry of Education, School of Mechanical Engineering, Shandong University, Jinan 250000, China; munishguptanit@gmail.com

4 Department of Automated Mechanical Engineering, South Ural State University, Chelyabinsk 454080, Russia; danil_u@rambler.ru

5 Department of Mechanical Engineering, Sinop University, Sinop 57000, Turkey; msarikaya@sinop.edu.tr

6 Department of Mechanical Engineering, Imperial College London, London SW7 2AZ, UK

7 Design, Manufacturing \& Engineering Management, University of Strathclyde, Glasgow G1 1XJ, UK

* Correspondence: c.pruncu@imperial.ac.uk or catalin.pruncu@strath.ac.uk

check for updates

Citation: Tayal, A.; Kalsi, N.S.; Gupta, M.K.; Pimenov, D.Y.; Sarikaya, M.;

Pruncu, C.I. Effectiveness

Improvement in Manufacturing

Industry; Trilogy Study and Open Innovation Dynamics. J. Open Innov. Technol. Mark. Complex. 2021, 7, 7. https://doi.org/10.3390/ joitmc7010007

Received: 11 November 2020 Accepted: 25 December 2020 Published: 30 December 2020

Publisher's Note: MDPI stays neutral with regard to jurisdictional clai$\mathrm{ms}$ in published maps and institutional affiliations.

Copyright: (C) 2020 by the authors. Licensee MDPI, Basel, Switzerland. This article is an open access article distributed under the terms and conditions of the Creative Commons Attribution (CC BY) license (https:// creativecommons.org/licenses/by/ $4.0 /)$.
Abstract: The purpose of this investigation is to compute overall equipment effectiveness (OEE) in the small-scale industry. The novel approach is introduced to detect bottlenecks by which OEE can be improved. This study attempts to help small-medium enterprises in analyzing performance in a better way. The automotive industry was chosen for conducting the research. The present study is comprised of three phases. In the first phase, OEE was computed and compared with world-class manufacturing. The second phase included three-level of Pareto analysis followed by making fishbone diagram to mitigate the losses. The third phase conducted improved OEE in the industry. There are seven major losses present in the industry that adversely affect the effectiveness of machine in any industry. This approach can reduce these losses and improve the quality, asset utilization (AU), OEE, total effective equipment performance (TEEP) and productivity of the machine. The study exposes that Pareto analysis uncovers all the losses and works on the principle of 80/20 rule. The major losses were thoroughly explored with the help of the fishbone diagram and solutions were implemented at the shop floor. As a result, availability, performance, quality, OEE, AU, and TEPP show improvements by $4.6 \%, 8.06 \%, 6.66 \%, 16.23 \%, 4.16 \%$, and $14.58 \%$, respectively. The approach offers a good opportunity for both researchers and small-medium enterprises around the world to analyze the indicators of production losses, performance, and productivity in the manufacturing industry.

Keywords: manufacturing industry; pareto analysis; fishbone diagram; asset utilization; overall equipment effectiveness

\section{Introduction}

The numerous considerations such as demand for a quality product at cost-conscious value, competition, exploration of new technology make reliability more critically during their design [1]. Recent advancements reveal an incredible improvement in the use of reliability engineering due to more intricate and advanced systems, which cater to the needs of the customer-driven market inefficient manner [2]. The reliability engineering was categorized into the specialized area. Data-driven and multi-function governance team are two characteristics which lead the world-class manufacturing system by promoting higher efficiency and satisfaction among internal and external customers. Reliability engineering faces a wide variety of challenges in today's industrial transformation. Reliability shows 
impressive progress for maintaining the industries, but the numerous factors such as intricacy, cost comparison, and competition make reliability more difficult in this era. Automotive trains, nuclear devices, space outposts, aviation, computers, and railways are some of the spiral typical systems that affect our daily lives, and, therefore, they need to be more reliable to support satisfactory operation without fail. These allocated systems are seriously affected, directly or indirectly, by specific factors i.e., high procurement cost, complexity, safety, reliability, quality, and universal competition.

The reliability factors reveal that the fruitful execution of product design and its operation phase-only results from the coordination among distinct specialists specifically from a quality, maintenance, and reliability departments, having cross-functional knowledge to retain the triumph of industrial establishment [3]. Manufacturing systems are generally recognized by sequential production activities involved in the conversion of raw material into tangible goods as initiated by planning and completed by sales and management. These systems are capitalized with a considerable amount for design and implementation of numerous types of equipment and machinery to nurture production movements at consistent supply with marginal scrap. Manufacturing systems are labeled with distinct features such as delivering essential human services, building nations' prosperity and strides for global reconciliation and human contentment. The integration and coordination among various flows (the flow of material; the flow of data; and the flow of cost) result in effective manufacturing movements. Material flow includes conversion of raw material into tangible goods, information flow comprises of planning and control of production movements, and cost flow embraces economical production. The flow of information, material, and cost play vital role in effective manufacturing system; hence, enhancing equipment reliability is the promising and major targeted area in the industry to maintain healthy relationships among production and market demand [4]. Equipment failure triggers two major issues such as non-production hours and non-compliance of demand for products. The severity of these issues can result in shrinking profitability and even company move out from the race of business. Maintainability can be deemed as an assistance tool to foster these issues; however, efficient and precise equipment directs to manufacture best quality and quantity commodities at right time for the market. The prime objective of an effective maintenance plan is to achieve profitable production by reducing downtime in the plant.

The unqualified labor force, unskilled operators, inadequate machine scheduling and planning are some of the major issues experienced by small scale industries which result in ineffectiveness of the manufacturing system [5-7]. Inadequate scheduling, planning, and unskilled operators prove more stoppages, less production time, and more quality defects; hence, these minor concerns must be properly addressed to counter all the ill effects on the manufacturing system.

Numerous techniques, tools, and plans are available such as affinity diagram, tree diagram, matrix diagram, arrow diagram, and process decision program categorized under management techniques. Cause and effect diagram, Pareto chart, check sheet, control chart, histogram, and scatter diagram can be shown as basic quality tools. Further, total quality management, total productive maintenance, just in time, lean production, and Kaizen can be sorted under philosophies. The success rate of any industry depends on accumulating data analytics for effective use of $5 \mathrm{M}$ (man, machine, material, methods, money) and uses this data for process improvement. Generally, alternative approaches are deliberate to mitigate the problems that occur repeatedly in the system. Existing works of literature are primarily fixated on the use of different techniques in numerous industries. Some of these studies are summarized as follows. Purba et al. [8] analyzed the Overall Equipment Effectiveness (OEE) with total productive maintenance method on cutting. For this, the researchers conducted a case study in the manufacturing industry. Their outcomes indicated that the highest OEE was $86.05 \%$ in July 2015 and the lowest OEE was $79.58 \%$ in August 2015. Chong et al. [9] presented the implementation of maintenance Failure Mode and Effect Analysis (FMEA) to develop OEE in a manufacturing company. The FMEA was performed with a five-step approach on a bottleneck process. Their outcomes showed that 
by taking the necessary precautions, machine availability can be improved and so high OEE can be achieved. Kapuria et al. [10] conducted a root cause analysis and productivity improvement in Bangladesh by using Kaizen implementation. They used Pareto analysis to identify defective items. With the implementation of the Kaizen implementation, the efficiency of the factory's production line was increased from $45 \%$ to $60 \%$. Nallusamy [11] studied the effectiveness and implementation of an independent maintenance system in a machine shop to improve OEE by using Total Productive Maintenance (TPM) and 5S implementation which are described as Sort, Set in order, Shine, Standardize, and Sustain. According to the research results, OEE was increased by $5 \%$ in the horizontal machining center and $7 \%$ in the vertical machining center. In another study, Nallusamy and Muthamizhmaran [12] emphasized the development OEE of the autoclave process with the implementation of time and motion works. Low et al. [13] studied enhancing the setup process of injection molding machines through the developed setup improvement method. They employed overall performance effectiveness (OPE) to analyze the setup development. The results showed that OPE is a good way to observe the process. Garza-Reyes [14] proposed overall resource effectiveness (ORE) to further improve the OEE. Hedman et al. [15] aimed to determine critical inputs and potential pitfalls while operating automatic measurement of OEE. In the study, they found OEE to be $65 \%$. In addition, almost $50 \%$ of recorded OEE losses could not be categorized. Azizi [16] proposed OEE as an indicator to determine equipment efficiency and, with the work done, it has been by improved $6.49 \%$. Puvanasvaran et al. [17] employed Maynard's Operation Sequencing Technique (MOST) in order to analyze the percentage development contributed to the OEE. A similar study was performed by the authors $[18,19]$. It is possible to extend studies conducted by Wolniak et al. [20], Wan et al. [21], and Salonitis and Kolios [22], who applied numerous tools in manufacturing, process, and service industries. Techniques are extensively used for improving the performance and effectiveness of numerous processes highlighted in the industry. The implementation of the combination of tools, techniques, and philosophies were methodically analyzed, investigated, and implemented by numerous investigators to maintain and sustain the processes by optimum use of resources during operation [12,14]. Yun et al. [23] discussed the entrance of new technology in market. In their work, they discussed the new channels and opportunities helpful in growth of open market. Yun et al. [24] also discussed the sustainability conditions of open innovation: dynamic growth of Alibaba from SME to large enterprise. In another work of Yun et al. [25], the culture about the open innovation dynamics has been discussed. Munir et al. [26] studied the open innovation tools in Sony mobile industry. Enkel et al. [27] discussed the open R\&D and open innovation phenomena in an industry.

Considering the literature information mentioned above, the present study proposed a new basis to increase the performance of an automotive manufacturing industry considered as micro, small, and medium enterprises (MSME). This paper demonstrates the effective utilization of Pareto analysis (PA), fishbone diagram (FBD), and overall equipment effectiveness (OEE) to mitigate the problems, which further spreads to increase the performance of the automotive industry. This study connects to essential information about collecting and analyzing the data in the industry. The results were thoroughly instructed and implemented in the industry.

Practitioners must be educated with the use and understanding of tools used to increase the effectiveness of any industry. The present study contributes not only to the terms of improving the effectiveness but also to create an impact on sustainability. This paper mitigates the losses by using optimized machining attributes on the machine. The machining attributes contribute more to improving the availability (less machine failure due to rated condition), performance (more material removal rate, less machining time, and better speed rating), and quality (less rejection and rework). It also helps to lessen the energy requirements during machining, failure time, and repair time. The objective of this research is to (I) surge productivity, (II) surge equipment life by increase responsiveness of the need for maintenance, and (III) decline cost. Outcomes of these research objectives are to 
(I) conquer competitive edge, (II) surge turnover, (III) recognize equipment proprietorship, and (IV) condense overheads.

The study is divided into different sections as follows. The research methodology adopted during this study is presented in Section 2. Section 3 presents the analyses and discussion with Pareto analysis, fishbone diagram, and overall equipment effectiveness. The conclusion is presented in Section 4 .

\section{Materials and Methods}

The present study is nurtured with a combination of Pareto analysis and fishbone diagram concept in the industry. Overall equipment effectiveness measures existing and later performance within the industry and the data was collected on the occurrence of losses arisen, possible causes, production, scrap, and downtime for one month in the automotive components manufacturing industry. The data is collected from the industry and it relates to the unsatisfactory performance of the manufacturing premise. The numerous reasons which reduce the performance of manufacturing premises are inappropriate maintenance, poor selection of tool material, non-optimized machining attributes, and setup time. This methodology helps in mitigate all these reasons in a well-organized way to improve the performance of the industry. The industry was visited several times for the prescribed period and observation was recorded for the working culture of an operator, working of maintenance, production, and quality personals. Figure 1 demonstrates the flowchart of the research methodology plan used in this study.

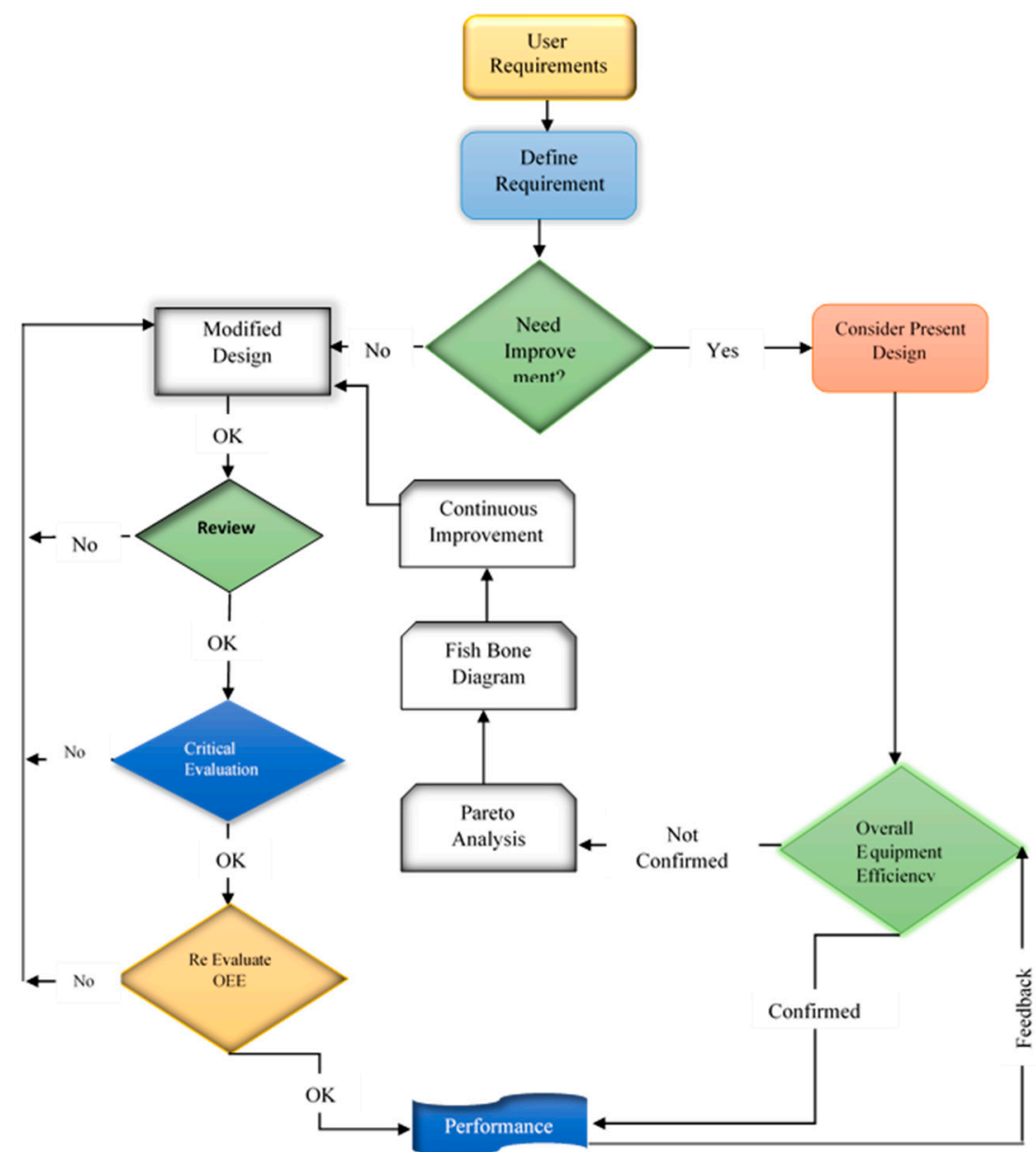

Figure 1. Flowchart of the research methodology plan used in this work. 
The research method adopted during this investigation not only focuses on performance improvement but tries to deliver the same information among the operator working in the industry.

The existing OEE was evaluated and compared; if it needed improvement, then Pareto analysis and fishbone diagram analysis were carried out. All the losses were mitigated through various strategies, tools, and techniques. OEE was re-evaluated and matched with the performance. If it was found okay, then changes are acceptable; otherwise, it was necessary to review the techniques and tools to improve the OEE. First, a familiarity about the method/techniques was discussed thoroughly among planning and maintenance teams to clear any misinterpretation that arose during observation and data collection. The observation for concerned machine tool procedure and other activities (planned shutdown time, unplanned downtime, scrap, breakdown) was carefully collected and investigated. The techniques like pro-active maintenance schedule, 5S approach in workstation, and autonomous maintenance approach shift the paradigm of an operator from "You to We." This involves the use of cutting tools as recommended by either the manufacturer or machine data handbook, regular training and monitoring of the process and persons employed in production, and initiating industry-institute interface (3 I approach) for healthier utilization of resources within and around the industry. The results were analyzed after implementation and convinced the employees to follow the improved methods and technologies in the industry. The objective of this research is to (I) surge productivity, (II) surge equipment life by increase responsiveness of the need for maintenance, and (III) decline cost. Outcomes of these research objectives are to (I) conquer competitive edge, (II) surge turnover, (III) recognize equipment proprietorship, and (IV) condense overheads.

\section{Overall Equipment Effectiveness}

The machine availability was the only parameter for evaluating equipment performance in an earlier era $[28,29]$. This methodology was used for comparison at the same output and same downtime. There is a high probability for speed loss due to start back up and quality forfeiture in form of scrap and rework, results from unforeseen stoppage. All the losses must be accountable, which can influence the capacity to mark output within the specified limit. The improvement actions must be prioritized for effective, better integration of all the losses. Equipment overall performance has set to be a more important indicator for calculating the performance of any industry and can be investigated through overall equipment effectiveness. This methodology can assimilate numerous factors availability, quality, and speed loss, so increasingly used in industrial atmospheres to evaluate the performance by comparing the theoretical maximum output and the actual output of the machine. The man, material, and procedure also take active participation in evaluating the effectiveness of a manufacturing plant. The performance of equipment and allied processes can be enhanced through recognizing prospects that reveal great influence on the production floor. The sustainability and reliability achievement reflects the efforts of planning and maintenance department with the concept of performability. Overall equipment effectiveness does not only mean ensuring reliability but it should also ensure sustainability. The ecological impact must be considered at each stage of operation to achieve sustainability in any industrial activity to counter the scarcity of resources in the 21st century. Clean production and knowledge can be envisioned for maximizing the yield by deploying the approach of reducing, recycling, and reusing in industries for minimizing the influence of production activities on ecology, which is the goal of performability.

Effective utilization of manufacturing operation can be effectively focused by the hierarchy sustained at various levels of OEE. The outcome of OEE allows the setting of benchmarks between different departments, machines, and operations within and around several industries. The useful and powerful individualities of OEE enables its use in easy monitoring and improving the efficacy of production line or machines. OEE is the multiplication of three important factors, namely, availability, performance, and quality loss. Figure 2 demonstrates the perfect model for OEE used in further study. Figure 2 
also shows various losses encountered during operation in industry and must properly be addressed to alleviate their effects on the OEE. The OEE can trace total productive maintenance implementation in the industry along with performance measurement of the system. World-class manufacturing industries have more than $85 \%$ OEE and to become a member of this elite class is among the goals of every company. The OEE score describes the performance of industry and is categorized into four levels: (i) OEE $>85 \%$ have excellent competitiveness; (ii) 70\% < OEE < 85\% considered good manufacturing facilities; (iii) $60 \%$ $<$ OEE $<70 \%$ fall under intermediate facilities; and (iv) OEE $<60 \%$ shows bad affordability.

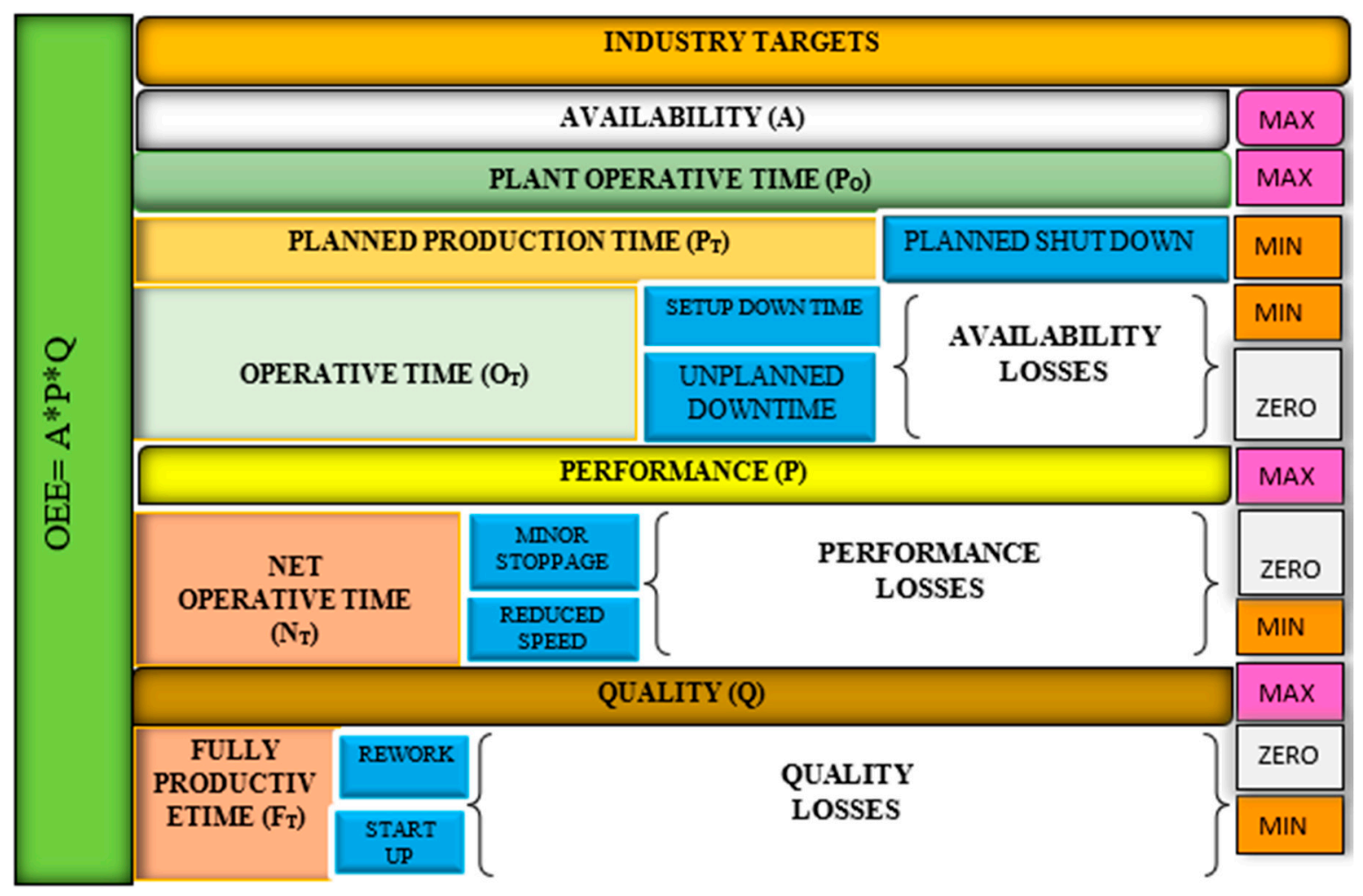

Figure 2. Overall equipment effectiveness (OEE) model.

\section{Results and Discussion}

Every industry wants to present itself in at least a second level of OEE performance metrics. Table 1 displays the key terms for the calculation of OEE and it has been observed that OEE and TEEP scores of $68.60 \%$ and $61.45 \%$ need improvement in their operation and scheduling. The OEE results from the combination of individual parameters that comprises losses at various stages. These losses must be tackled properly so that OEE can be improved. In this section, losses were tracked by Pareto analysis and fishbone diagram. OEE metrics were evaluated to counter the performance of an existing set of operations. Figure 2 reveals the seven big losses that take active contribution in degrading the numerical value of key metrics like OEE, AU, and TEEP (Figure 3). These seven big losses, namely, planned shutdown, setup downtime, unplanned downtime, minor stoppage, reduced speed, rework, and start-up, need to be scrutinized systematically.

\subsection{Pareto Analysis}

The Pareto analysis helps in scrutinizing these losses operatively and it can be extended to make a fishbone diagram for one of the major losses. The improvements were implemented internally and externally in the industry. Operational outcomes and economic prosperity are the basis of Pareto analysis, and the unevenness among these two vital parameters contribute to Pareto analysis. The $80 / 20$ rule is another name for Pareto analysis. 
Table 1. Key parameters of OEE.

\begin{tabular}{|c|c|c|c|c|c|}
\hline No. & Key Terms & Symbol & Formula & Value & Unit \\
\hline 1. & Plant Operating Time & $P_{O}$ & No. of shift $\times$ Working Hours & $1 \times 8 h r s .=8 h r s=480$ & Min \\
\hline 2. & Planned Shutdown Time & $P_{S}$ & $\begin{array}{l}\text { This includes short breaks/meal } \\
\text { breaks/preventive maintenance schedule }\end{array}$ & $\begin{array}{l}2 \text { Short Breaks@10 min } \\
=201 \text { Meal Break } @ 30 \\
\text { min }=30 \text { Total }=50\end{array}$ & Min \\
\hline 3. & $\begin{array}{l}\text { Planned Production } \\
\text { Time }\end{array}$ & $P_{T}$ & $\begin{array}{c}\text { Plant Operating Time }\left(P_{O}\right) \text { _Planned } \\
\text { Shutdown Time }\left(P_{S}\right)\end{array}$ & $480-50=430$ & Min \\
\hline 4. & Down Time & $D_{T}$ & $\begin{array}{l}\text { Downtime arises due to tooling failures, } \\
\text { unplanned maintenance, general } \\
\text { breakdowns, equipment failure, } \\
\text { setup/changeover, and material shortages }\end{array}$ & 40 & Min \\
\hline 5. & Operative Time & $O_{T}$ & $\begin{array}{c}\text { Plant Production Time }\left(P_{T}\right) \text {-Down } \\
\text { Time Loss }\left(D_{T}\right)\end{array}$ & $430-40=390$ & Min \\
\hline 6. & Ideal Cycle Time & $C_{T}$ & $\begin{array}{l}\text { The time needed to achieve the product in } \\
\text { a suitable time }\end{array}$ & 1 & Min \\
\hline 7. & Total no. of Pieces & $N$ & $\begin{array}{l}\text { Total production in a single shift during } \\
\text { planned production time }\end{array}$ & 330 & Count \\
\hline 8. & Minor Stoppages & $M$ & Misfeed, jams, sensor failure, etc. & 30 & Min \\
\hline 9. & Net Operating Time & $N_{T}$ & Operative Time-Minor stoppages & $390-30=360$ & Min \\
\hline 10. & $\begin{array}{l}\text { Efficient Net } \\
\text { Operating Time }\end{array}$ & $E_{T}$ & Ideal Cycle Time $\left(C_{T}\right) \times$ Total Pieces $(N)$ & $1 \times 330=330$ & Min \\
\hline 11. & Rejected Pieces & $N_{R}$ & $\begin{array}{c}\text { Total no of pieces which do not adhere } \\
\text { with the specification }\end{array}$ & 35 & Count \\
\hline 12. & Good Unit & G & $\begin{array}{l}\text { Total no of Pieces }(N) \text {-Rejected Pieces } \\
\qquad\left(N_{R}\right)\end{array}$ & $330-35=295$ & Count \\
\hline \multicolumn{6}{|c|}{ Availability } \\
\hline 13. & Availability & $A$ & $\begin{array}{l}\text { Operating Time }\left(O_{T}\right) / \text { Planned } \\
\text { Production Time }\left(P_{T}\right)\end{array}$ & $390 / 430=90.70$ & $\%$ \\
\hline \multicolumn{6}{|c|}{ Performance } \\
\hline 14. & Performance & $P$ & $\frac{\left[\text { Ideal Cycle Time }\left(C_{T}\right) \times \text { Total Pieces }(N)\right]}{\text { Operative Time }\left(O_{T}\right)}$ & $\frac{[1 \times 330]}{390}=84.62$ & $\%$ \\
\hline \multicolumn{6}{|c|}{ Quality } \\
\hline 15. & Quality & $Q$ & Good Units/Total Units & $295 / 330=89.39$ & $\%$ \\
\hline \multicolumn{6}{|c|}{ Overall Equipment Efficiency } \\
\hline 16. & $\begin{array}{l}\text { Overall Equipment } \\
\text { Efficiency }\end{array}$ & $O E E$ & $A \times P \times Q$ & $\begin{array}{c}90.70 \times 84.62 \times 89.39 \\
=68.60\end{array}$ & $\%$ \\
\hline 17. & Asset Utilization & $A U$ & $\begin{array}{c}\text { Operating Time }\left(\mathrm{O}_{T}\right) / \text { Plant Operating } \\
\text { Time }\left(P_{O}\right)\end{array}$ & $390 / 480=81.25$ & $\%$ \\
\hline 18. & $\begin{array}{c}\text { Total Effective } \\
\text { Equipment performance }\end{array}$ & TEEP & $A U \times P \times Q$ & $\begin{aligned} 81.25 \times & 84.62 \times 89.39 \\
& =61.45\end{aligned}$ & $\%$ \\
\hline
\end{tabular}

It is a column graph type diagram drawn from the collected data, and the graph differentiates between the vital factors and trivial ones. The priorities were fixed on the selected problem serially after data collection. The major factors were tackled, which were more responsible for a specific problem. The problems were recognized, categorized, and grouped based on their reoccurrence and anticipated in form of a percentage. The abscissa represents factors arranged in descending order and vertex as percentage contribution. The graph shows its importance in the system and emphasizes the vital area rather than the trivial one. Figure 4 demonstrates the first level Pareto analysis of the various losses 
in the system. Draw a horizontal line across the $80 \%$ and draw a vertical line through its intersection on the abscissa. The area excluding $80 \%$ intersection attracts more to deal with these big losses in an effective manner. The chart reveals that reject/rework and minor stoppage along with speed loss must be properly monitored and needs to be thoroughly analyzed. The planned downtime is considered to be one of the seven losses and needs to be minimized so that planned production time can be increased. The planned downtime comprises two short breaks and one meal break for the operator. This loss cannot directly take contribution to affect speed loss and quality loss.

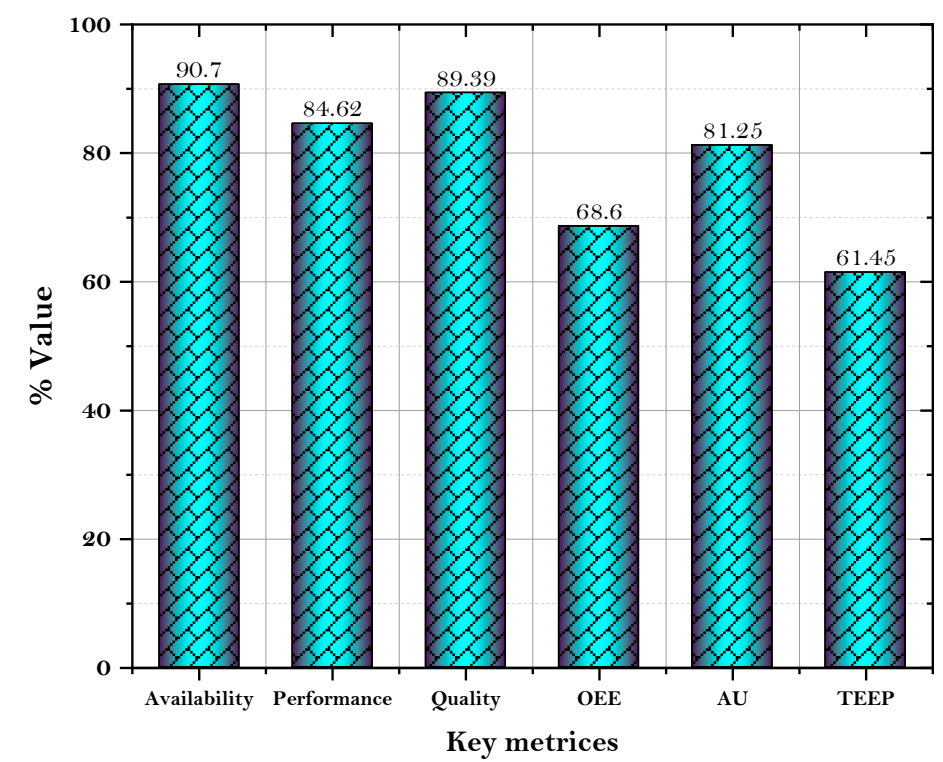

Figure 3. Performance value of key parameters.

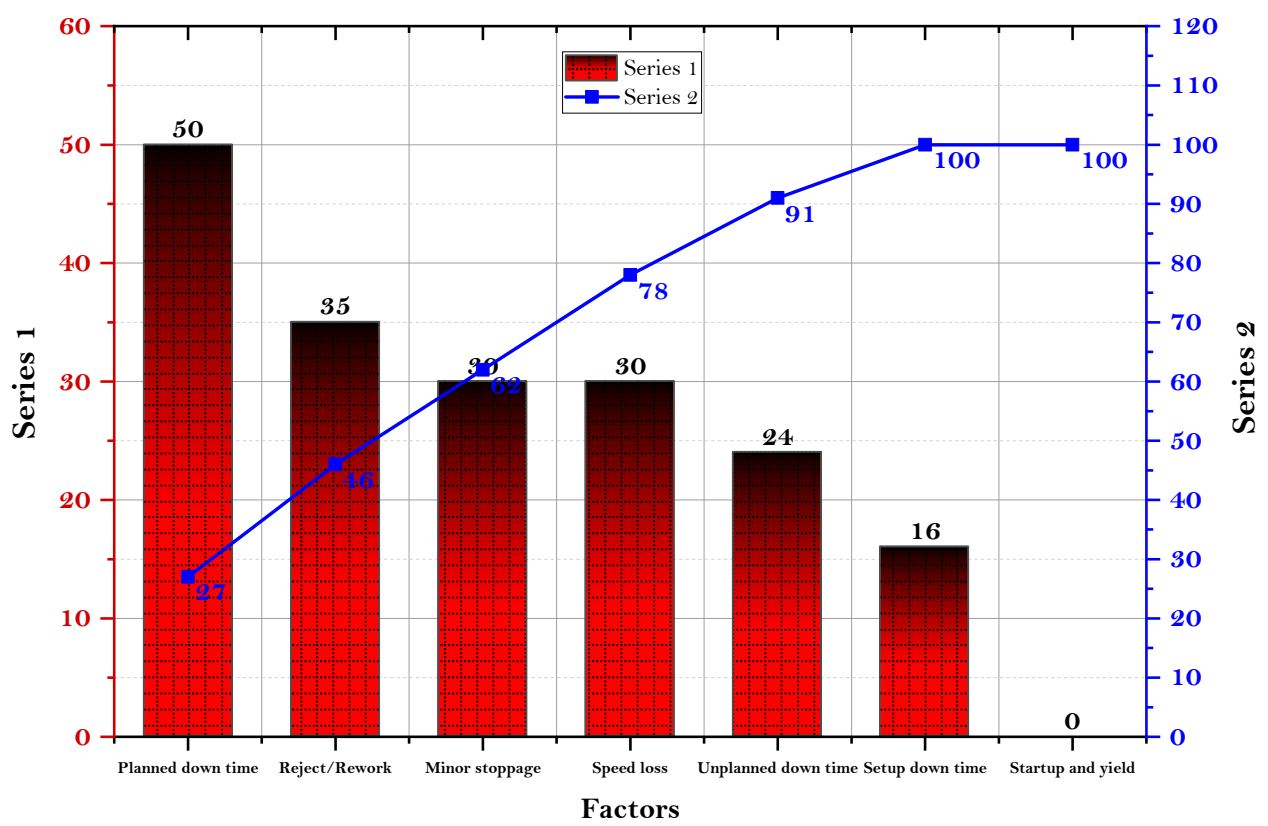

Figure 4. First Level Pareto analysis of big losses in OEE.

This time can be effectively utilized for performing the scheduled maintenance activities so that unplanned time can be inevitably cut down to some extent. The further study put more emphasis on the remaining three losses reject/rework, minor stoppage, and speed loss. 


\subsection{Fish Bone Diagram (FBD) Analysis}

The prime objective was to make a broad understanding of factors that adversely affect the seven losses in the system. Based on the observation, these factors were characterized as technical subjects, people development subjects, and management subjects. These subjects were tackled properly by coordinate the technical subjects with a cross-functional team, people development subject with production area-based team, and management subject with managerial officials. The data was collected and an effective management tool was used to present this data efficiently. Fishbone diagram (FBD) uses an illustrative representation of causes and their effects and can be a much effective tool for a specific case [30]. The FBD shows its usefulness due to graphical appearance, which makes this tool highly effective for analyzing the production problem. If there is a cause, then the effect must be present within the system and vice versa. The diagram with suitable branches and sub-branches (twiglets) effectively shows their relation. Fishbone diagram needs to be drawn according to logic and follow the steps listed below:

1. The problem that was analyzed must be put into the right side of the fishbone diagram, sketch the skeleton with right side pointed arrow.

2. The effective causes of the problem, e.g., method, material, man, environment, and machine, are categorized into the main fishbone.

3. The main causes as mentioned in the second step need to be excavated thoroughly. The consequent causes are treated as middle fishbone and one cause represents one fishbone only.

4. The cause is further expanded until it reaches its maximum. The numerous branches can be draw laterally on the skeleton through middle and small fishbone. Use an appropriate name and place with arrows.

5. This complete step-by-step procedure is called FBD as it looks like a spiky fishbone.

The fishbone diagram for the losses as interpreted from Pareto analysis was drawn and explained. Rework, speed loss, and minor stoppage were taken into consideration for FBD. Figures 5-7 demonstrate the various causes associated with these losses and, hence, FBD was successfully drawn by adopting the above-listed procedure. The performance was enhanced by considering certain causes, and the source of individual problems was systematically analyzed through the 5-why technique.

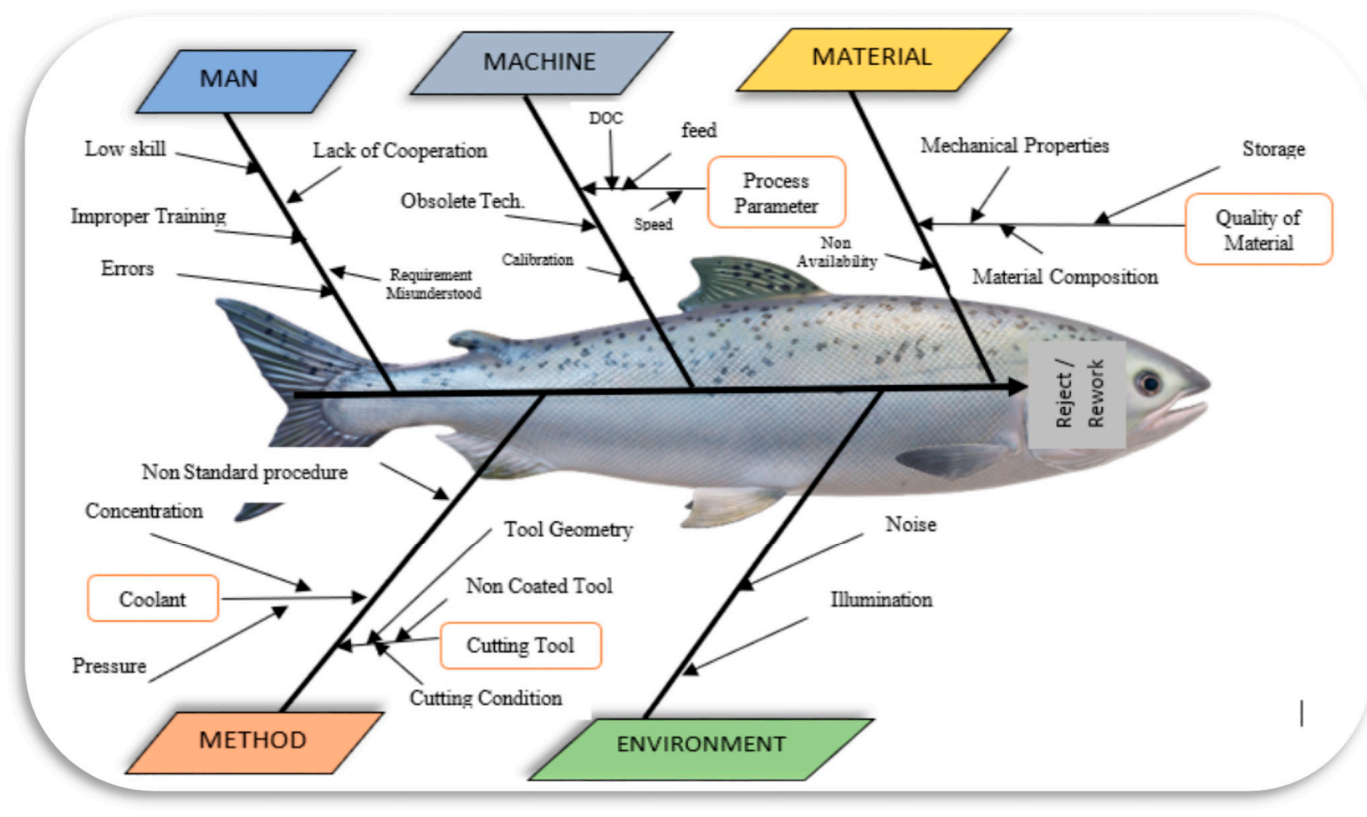

Figure 5. Fishbone diagram for rework/reject. 


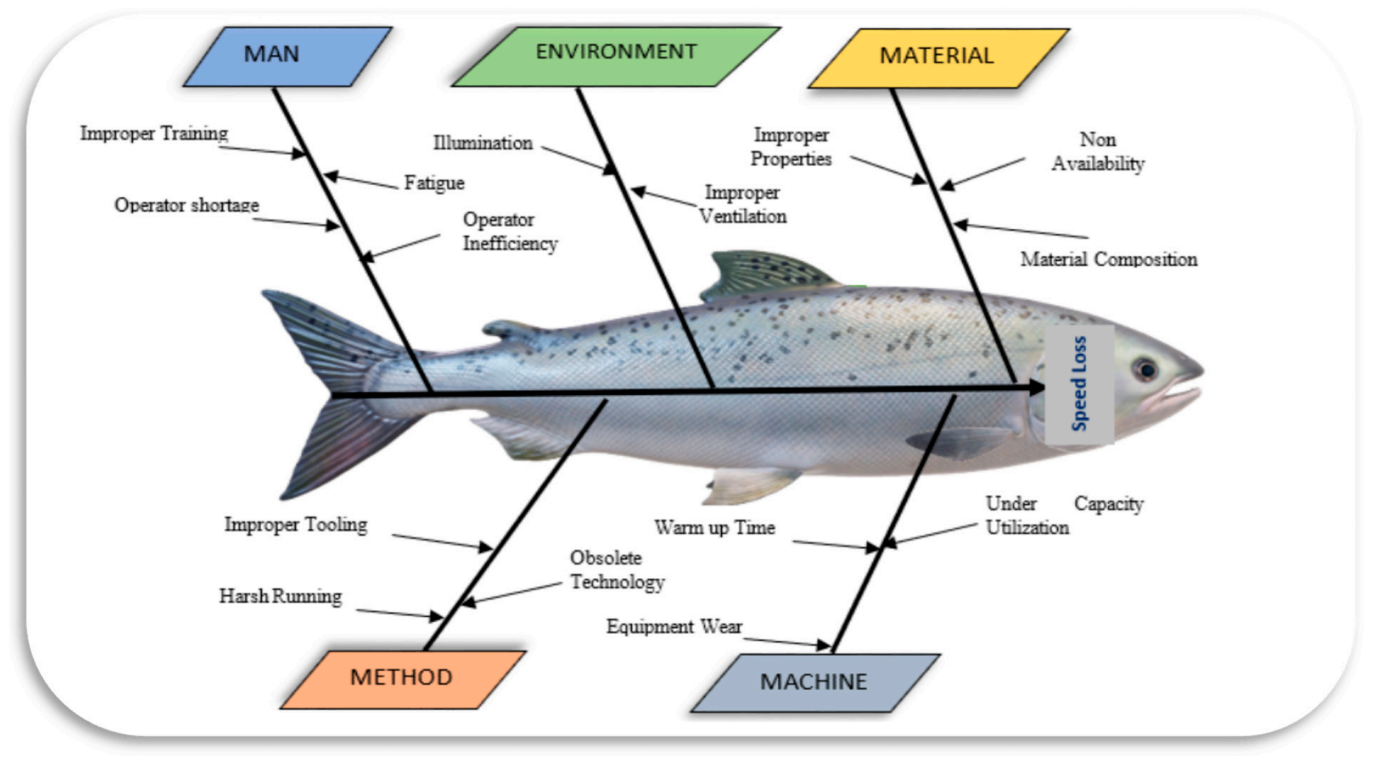

Figure 6. Fishbone diagram for speed loss.

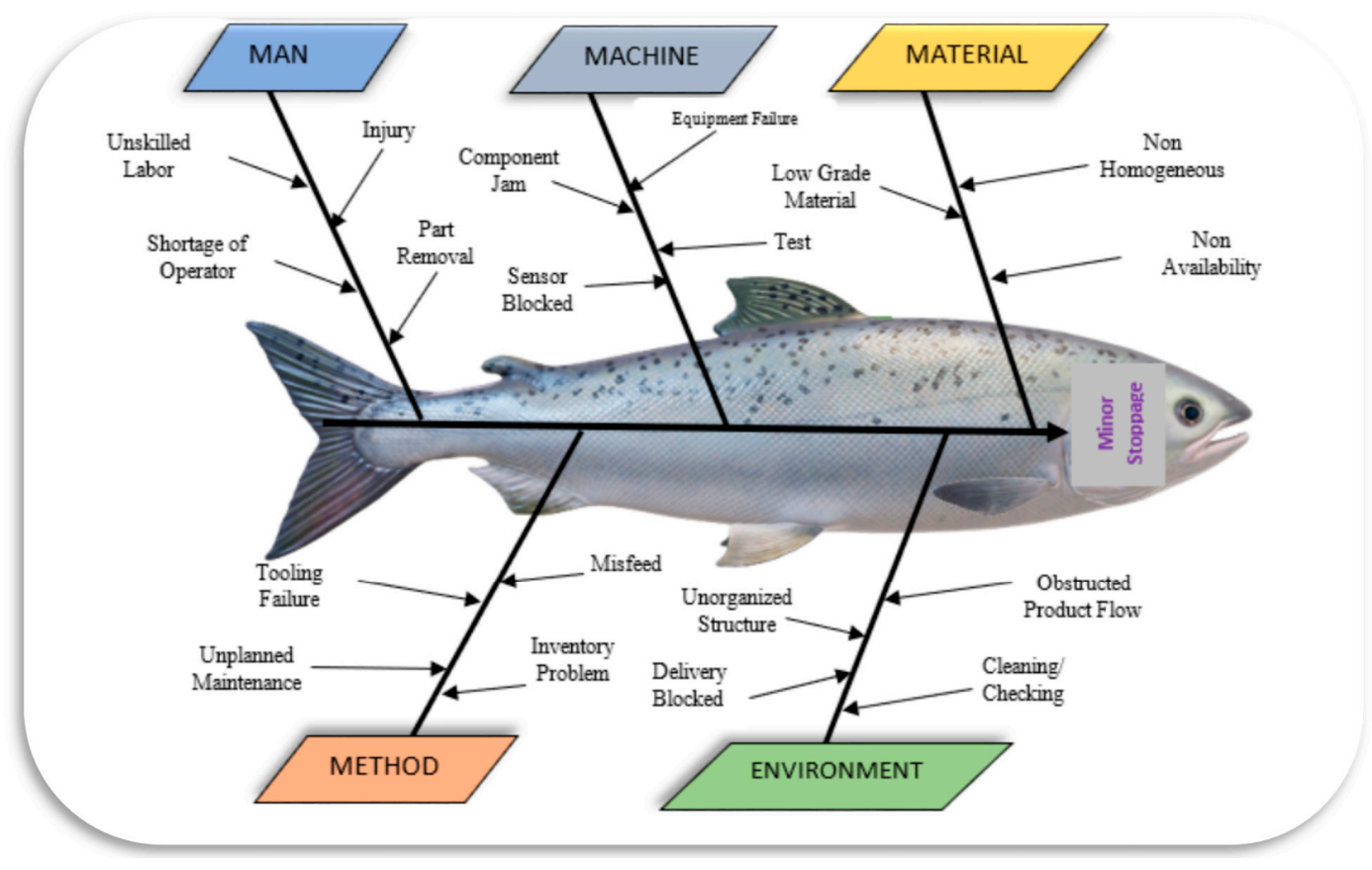

Figure 7. Fishbone diagram for a minor stoppage.

Figures 5-7 reveal that the major losses result from $5 \mathrm{M}$ and comprise of numerous causes, which decrease the time available for the planned production time. The reappearance can be diminished by proper converging on the FBD. FBD analysis helps a lot in lowering the losses. Industries fail to meet the demand even running 24/7. The steady production level can be maintained by reducing these various causes, which leads to unwanted stoppage during production. The 2 nd level Pareto analysis for major causes was framed as shown in Figure 8 and demonstrates the higher percentage of common causes for speed loss, minor stoppages, and reject/rework.

The chart reveals that tooling failure, unplanned maintenance, process parameter, and improper training fall under $80 \%$ and need to be addressed properly to alleviate the different losses. These four major issues resolve many issues that directly or indirectly affect the performability of an industry. 


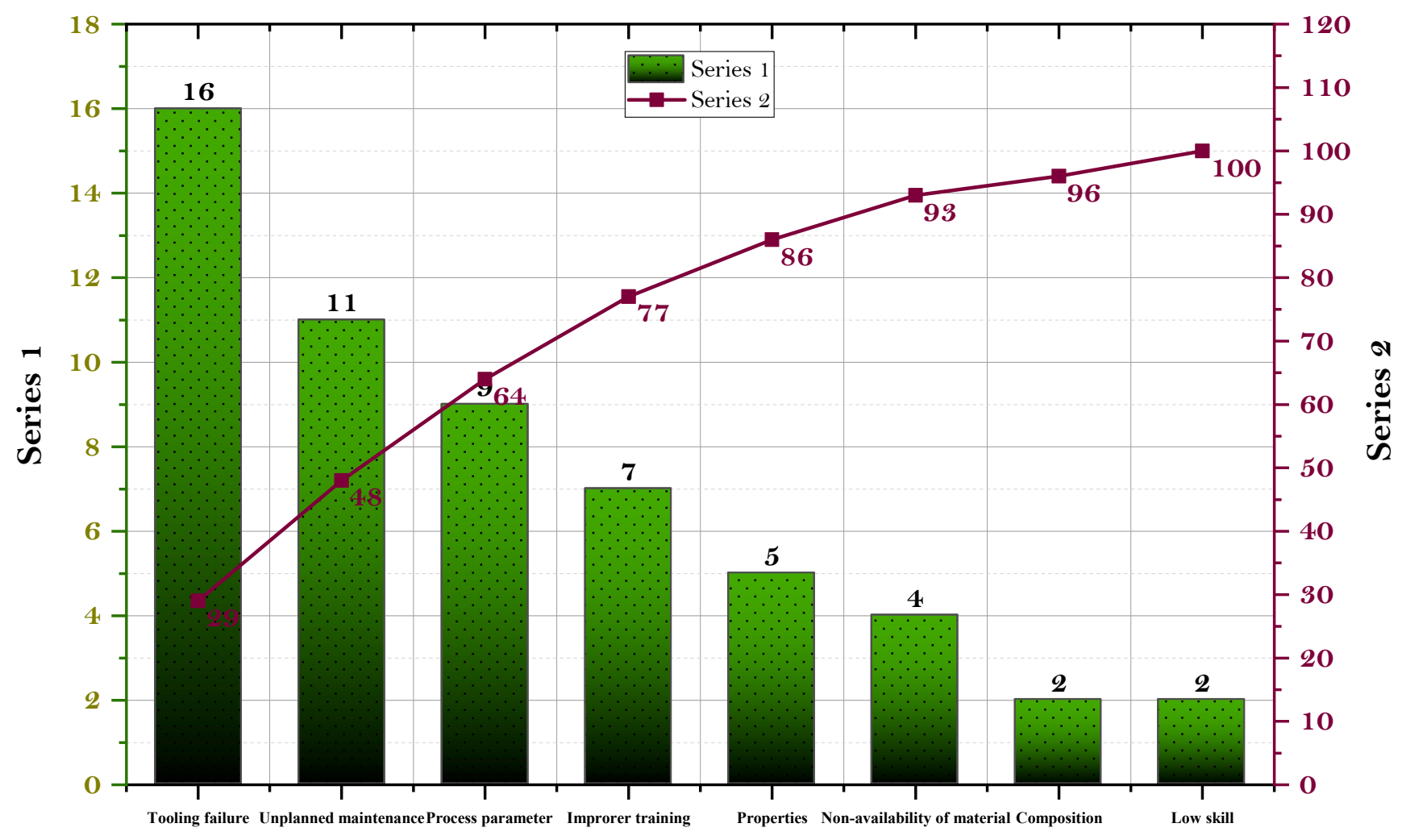

Factors

Figure 8. Second Level Pareto analysis for common causes.

\subsection{OEE Improvement Practices}

\subsubsection{Tooling Failure}

This paper reported the study of the automotive industry. Three 8 -hr shifts are scheduled with several machines. In this work, machine number 20 was selected for a comprehensive study. The stepwise detailed analysis revealed that numerous causes participate in poor performance of operations. The tooling failure contributes further to reducing the planned production time and occurs for various causes [31-34]. The tooling consists of a cutting tool and other accessories. The study shows that frequent tooling failure adversely affects speed loss, minor stoppages, and reject/rework and consequently has an effect on the performance of the industry. An operator must verify the condition of the cutting tool after regular intervals of time and, if needed, the tool must be either replaced or sharpened to resume with the operations. These regular stops during the process create unplanned time loss in form of tool failure, increased downtime, and further diminished availability of the system; creates minor stoppage and speed loss in the form of reduced capacity and results shrunk in performance of the system; and creates reject/rework that results from faded cutting edges during operation in the form of poor-quality products and, hence, the quality rating is hampered. During interaction with the shop floor staff, it was concluded that the solid cutting tools selected do not adhere with the recommendation of the manufacturer catalogue and are inappropriate with the workpiece material. The condition of the solid cutting tool is inspected by the operator to check its usability within short time intervals. The worn-out tool needs to be ground again to resume the operation and sometimes the tool is not to be ground as per the specified tool geometry, which causes severe surface defects. The higher authorities were communicated with suggestions as shown in Figure 9. 


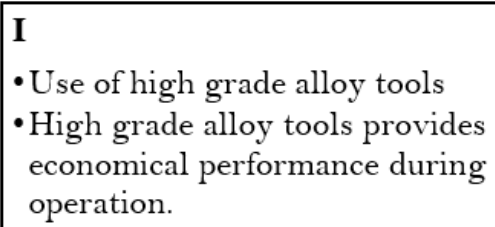

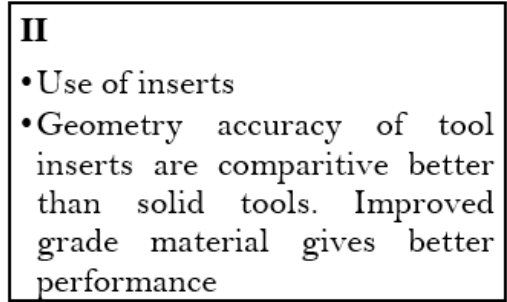

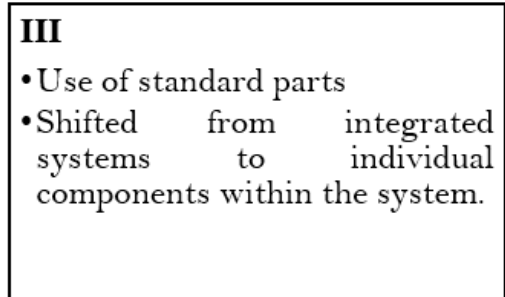

Figure 9. Suggestion to mitigate tooling failure.

\subsubsection{Unplanned Maintenance}

Unplanned maintenance causes unadorned problems in the system, increased downtime, hampered production activities, reduced speed loss, minor stoppage, and reduced quality rate due to sudden breakdown on the machine tool. The manufacturing industries performance depends upon machine tools, and failure of these can put adverse effects on fulfilling customer demand. The failure also creates ambiguities on the shop floor and hence obstructs their efficiency and creates more monetary deficits. Manufacturing systems heart includes machine tools and needs to maintain these tools efficiently for healthy breathing of the system. Therefore, planned maintenance or proactive maintenance strategies must be adopted to prevent such uncertainties in the system. Deficiencies during preventive maintenance result in corrective maintenance, which is to bring a piece of equipment to its original order. Unplanned maintenance also causes corrective maintenance and needs to stop the production activities until the equipment returns to its operational state. Therefore, corrective maintenance and preventive maintenance need to be optimized for a reduction in downtime and the same has been suggested and discussed with the management team.

Corrective maintenance downtime includes three basic modules as listed and explained in Table 2. The corrective maintenance efficacy increases by adopting strategies in the plant. The strategies follow in the industry were explained as follows:

1. Improve interchangeability: This concept is useful in lowering maintenance time; the inclusion of interchangeability during replacing and removing parts consumes less time and further extends planned production time.

2. Improve fault acknowledgement, position, isolation: These three main activities consume the most time in the industry. Faults can be timely acknowledged and positioned through effective maintenance procedure and well-trained personnel employed in the industry. Effective training helps to diagnose and locate the fault through minimal efforts within the system. Vibration monitoring, oil particle analysis, and thermal imaging are some of the approaches by which faults can be easily positioned and isolated. An effective troubleshooting procedure easily monitors and recognizes the fault. The indisputable fault isolation provides more accuracy in the time.

3. Human factors: The ergonomically designed components help to mitigate the corrective maintenance time. The various components, pointers, and dials must be arranged ergonomically on the machine as per their size, shape, and weight criterion. This practice reduces efforts as well as time to convert failure state into operational state within minimal time.

4. Use redundancy: The redundancy in the system will reduce the load on the production line in case of breakdown or failure in the line. The redundant components can be exchanged any time for the period of failure of the specific component for maintaining continuity in the system. Even though whole maintenance may not be affected, the equipment downtime decreases appreciably. 
Table 2. Corrective maintenance downtime modules.

\begin{tabular}{ll}
\hline & $\begin{array}{l}\text { AdministrativeandLogisticTime: } \\
\text { Time taken for implementing decision through administrative department } \\
\text { and provide the same without any hinderence. }\end{array}$ \\
\cline { 2 - 2 } $\begin{array}{c}\text { Corrective } \\
\text { Maintenance } \\
\text { Down Time }\end{array}$ & $\begin{array}{l}\text { Time taken to convert the failure state into operational state. This will } \\
\text { depend upon checkout, preparation, fault correction, location, adjustment } \\
\text { and calibration, and spare item time. }\end{array}$ \\
\cline { 2 - 2 } & $\begin{array}{l}\text { Delay Time: } \\
\text { The actual time taken by the system from the scheduled time referred as } \\
\text { delay time. }\end{array}$ \\
\hline
\end{tabular}

Preventive maintenance reduces the risk of severity of breakdown/failure in the system. The effective maintenance schedule leads to less unplanned downtime. Preventive maintenance comprises various elements as shown in Figure 10. These elements effectively help the maintenance team to reduce the above-mentioned risks and failure.

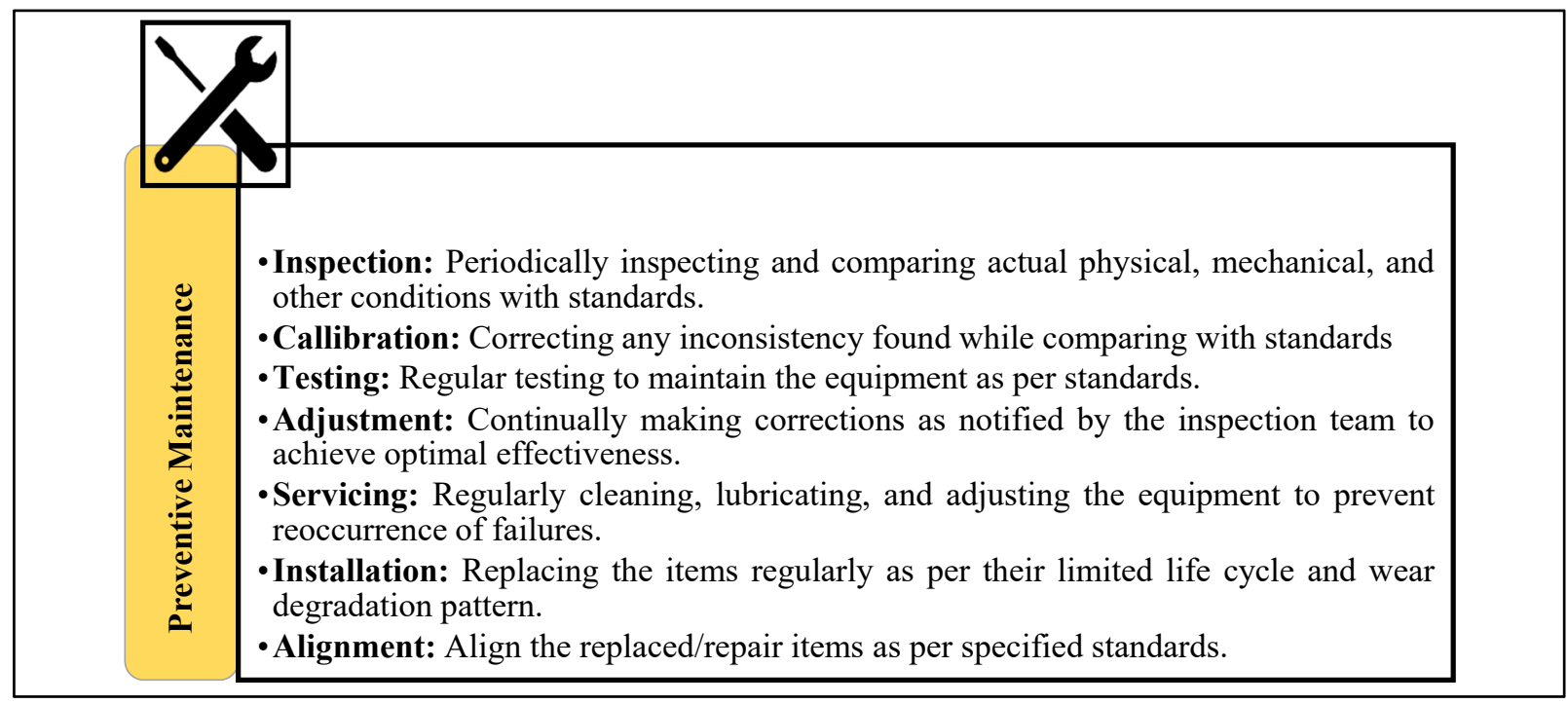

Figure 10. Elements of preventive maintenance.

Availability of necessary support such as testing instrument, tools, a past database of equipment, skilled labor, manufacturer index, management cooperation, and manuals leads to an effective preventive maintenance program. First, the area must be chosen for initiation of maintenance effort. The maintenance requirements prioritized, based upon priorities of maintenance activities, were developed through daily and periodic inspections. Maintenance events occurrence were recorded and reviewed properly to make an effective daily and periodical maintenance plan. The final plan for both the types was approved and executed at the shop floor level for desired results. The effective stepwise procedure helps to minimize the planned downtime for maintenance purposes.

\subsubsection{Process Parameters}

The status of the process was measured concerning certain indicators and values. These values are known as process variable or process parameters. The parameters must be under uninterrupted control for effective use of equipment. The measured parameter always results in improved performance without affecting the system. The overall system performance can be acquired efficiently when process parameters are used to count machine reliability. As the process parameter changes, it will disturb the production rate, performance, and probability of failure of a given system. The inclusion of parameter per- 
mits improved estimation of an overall performance rate. These parameters are influenced by workpiece formation and material. Therefore, proper selection of these parameters results in increased planned production time, reduced time, reductions in six big losses, and increased economy. Generally, three parameters i.e., cutting speed, depth of cut, and feed are considered for evaluation. Optimized machining attributes result in less tooling failure and consequential losses are reduced. If losses are reduced, then it leads to an increase in the effectiveness of the industry [35-39]. The cutting speed, expressed in meters per minute $(\mathrm{m} / \mathrm{min})$ or feet per minute $(\mathrm{ft} / \mathrm{min})$, is the path traveled by a point on the cutter. Literature reveals that using extremely slow cutting speed is unviable for production and extremely high cutting speed is unworkable for economical production [40]. The most viable cutting speed must be chosen for a workpiece tool interface without affecting performance and economy [41,42]. While selecting optimal cutting speed, feed (as per cutting tool strength and surface finish requirement) and depth of cut (machine tool, cutting tool and system requirement), all outcomes should be considered. Production efficiency comprises machining time, tool changing time, setup time, and costs associated with them. The proper selection of parameters results in optimal production rate $\left(P_{r}\right)$ and production cost $\left(C_{p}\right)$, as can be seen from Equations (1)-(4).

$$
\begin{gathered}
T_{p}=T_{i}+M_{t}+\operatorname{Tch} \frac{N_{t}}{N_{b}}, T_{p}=T_{i}+M_{t}+T c h \frac{N_{b} \times M_{t}}{N_{b} \times T} \\
T_{\text {edge }}=T_{c h} \frac{M_{t}}{T} \ldots ; M_{t}=\pi d l / 1000 V_{c} f \\
T_{p}=T_{i}+M_{t}+T_{\text {edge }} \\
C_{p}=\left(K_{1} \times M_{t}\right)+\left(K_{1} \times T_{i}\right)+\left(K_{1} \times T_{\text {edge }}\right)+\left(K_{2} \times M_{t} / T\right) \\
T_{p}=T_{i}+M_{t}+T c h \frac{N_{b} \times M_{t}}{N_{b} \times T}
\end{gathered}
$$

The machining economics helps to choose the process parameters to minimize the production unit time $\left(T_{p}\right)$, which comprises of load/ unload time $\left(T_{i}\right)$, actual machining time $\left(M_{t}\right)$, and the average time spent in changing insert tip (Tedge). $N_{b}$ is the total components produce a batch, $N_{t}$ is the total number of tools used. $K_{1}, K_{2}$ are man-machine hour rate $(\$ / \mathrm{min})$ and the cost of consumable per cutting edge (\$). The appropriate tool material (high-grade material), tool geometry (positive, neutral, and negative), tool inserts (Physical Vapor Deposition and Chemical Vapor Deposition), and optimal process parameter strongly influence the availability rate, performance rate, and quality rate. Equations (1)-(4) reveal that production time is dependent upon machining time, and further machining time shows the relation between cutting speed and feed. Equation (5) displays the tool life equation, where $\mathrm{C}, \mathrm{n}, \mathrm{n} 1$, and $\mathrm{n} 2$ are the constant depending upon the tool material. Also, $\mathrm{C}$ depends on the tool-workpiece material interface and helps to trace out the availability rate of the machine. Less tool life means more tool changing and less machine available, and vice versa. Repeated tool changing increases minor stoppages and reduces the speed, and so affects the performance rate of the industry. Abrupt breakage in the tool seriously damages the workpiece surface and sometimes the machine tool is also affected by these abrupt impacts, which leads to reject/rework, and hence affects the quality rate. The tool wear is highly influenced by cutting speed, feed, and depth of cut, and results in poor dimensional accuracy, process stability, and surface finish, causing reject/rework as shown in Figure 11. The same results were reported by Murat et al. in their scientific works [43]. 


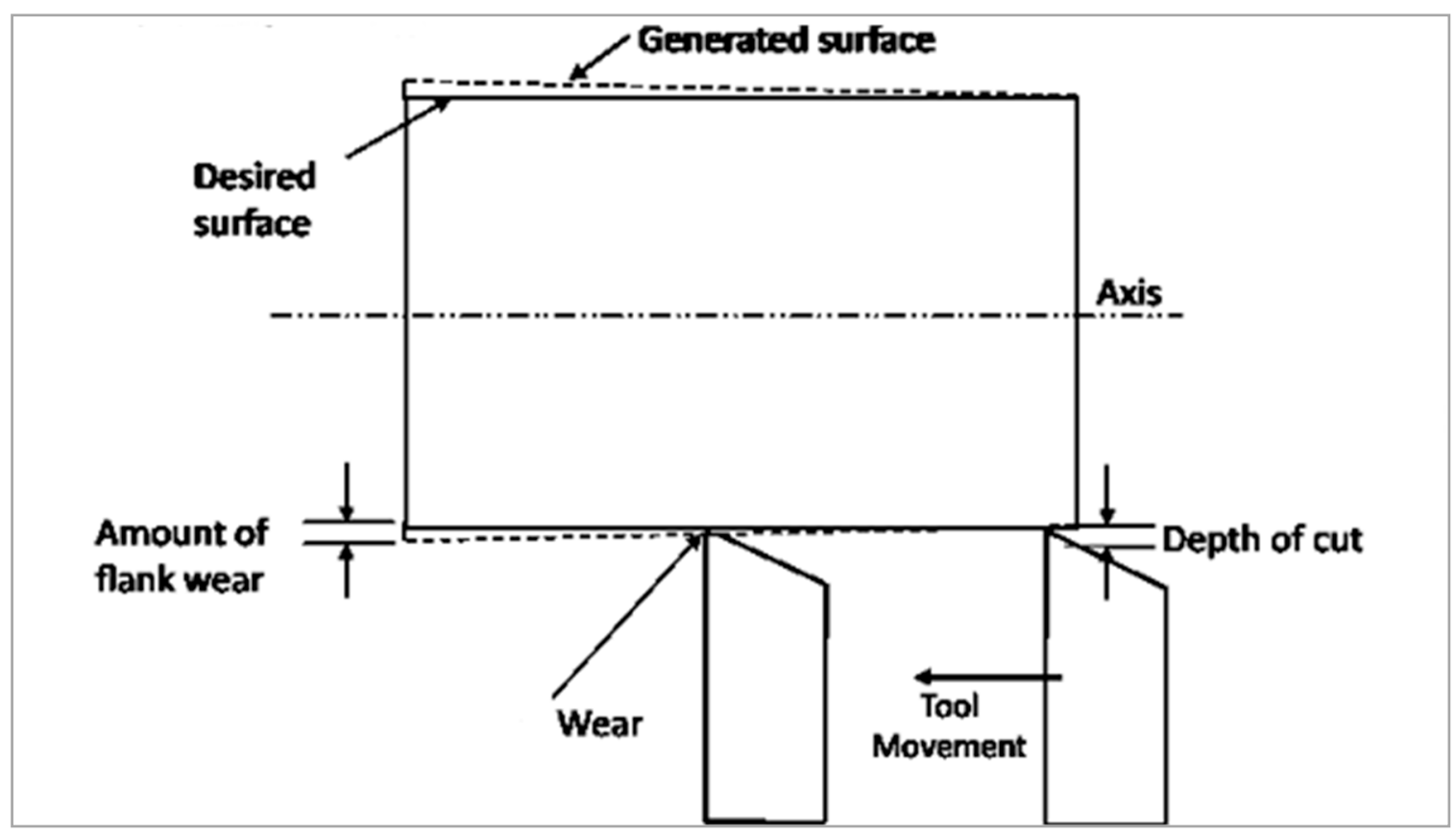

Figure 11. Effect of tool wear on the machined surface.

\subsubsection{Improper Training}

Training greatly affects the overall performance of the industry. Third level Pareto analysis reveals that improper training was considered one of the main causes as per the $80 / 20$ rule and, hence, needs to be tackled to improve the performance in the industry. If the workforce is properly trained, then most of the problems routinely disappear from the machine area. A skilled workforce understands the effects of following non-standardized procedure during the machining operation. The motive of addressing tooling failure, unplanned maintenance, and process parameter is to mitigate the big losses that can result from the unskilled worker. Unskilled workforce needs to undergo training to fortify their skills as well as utilize their improved skills in improving the overall effectiveness of the industry. The effect of these minor changes is observed during the operation. Labor is reinforced with the training of $5 \mathrm{~S}$ terminology and autonomous maintenance in the industry to keep industry progressive in nature.

\subsubsection{5'S Methodology}

Every organization deals with poor effectiveness due to waste in the form of either defect, waiting time, superfluous motion, surplus inventory, extra processing, pointless conveyance, and unutilized talents. This technique helps to increase performance by maintaining the workplace clean, reliable, well managed, and uncluttered. This technique not only recognizes five words but helps the organization to reduce wastage and losses. The industry faces too much-unplanned downtime due to cluttered organization. The 5'S methodology is the right technique to conquer cluttered organization. The shop floor scan cum diagnostic sheet was prepared and successfully communicated with management team for improvement in the industry, as demonstrated in Table 3. The sheet rated five levels from L1 to L5. If more than four problems occur, then L1 is written in the sheet; three problems mean L2; two problems mean L3; 1 problem means L4; and zero problem means L5. 
Table 3. Shop floor scan cum diagnostic sheet.

\begin{tabular}{|c|c|c|c|c|c|c|c|c|c|}
\hline \multirow{2}{*}{\multicolumn{2}{|c|}{ Classification }} & \multirow{2}{*}{\multicolumn{2}{|c|}{ Descriptions }} & \multicolumn{5}{|c|}{ Rating } & \multirow[t]{2}{*}{ Remarks } \\
\hline & & & & L1 & L2 & L3 & L4 & L5 & \\
\hline \multirow{6}{*}{$\mathbf{A}$} & \multirow{6}{*}{$\begin{array}{c}\text { SEIRI } \\
\text { ORGANIZE } \\
\text { (SORT) }\end{array}$} & 1. & Distinguish between wanted and unwanted items & & & & & & \\
\hline & & 2. & Unwanted equipment, tool, other items on the shop floor. & & & & & & \\
\hline & & 3. & Purpose of the items, frequency of use & & & & & & \\
\hline & & 4. & Unwanted items in the staircase, corners. & & & & & & \\
\hline & & 5. & Unwanted items on walls and information board. & & & & & & \\
\hline & & 6. & Unwanted inventory supplies or materials. & & & & & & \\
\hline \multirow{5}{*}{ B } & \multirow{5}{*}{$\begin{array}{c}\text { SEITON } \\
\text { UNIFORMITY } \\
\text { (SET IN ORDER) }\end{array}$} & 7. & A place of everything and everything in its place. & & & & & & \\
\hline & & 8. & Items are not in order & & & & & & \\
\hline & & 9. & Workstations, items location not demarcated & & & & & & \\
\hline & & 10. & Correct items not grouped & & & & & & \\
\hline & & 11. & Quantity limits are not appropriate & & & & & & \\
\hline \multirow{6}{*}{ C } & \multirow{6}{*}{$\begin{array}{c}\text { SEISO } \\
\text { CLEANLINESS } \\
\text { (SHINE) }\end{array}$} & 12. & Cleaning and looking ways are not organized & & & & & & \\
\hline & & 13. & Workplace area, floor, stairs are contaminated & & & & & & \\
\hline & & 14. & Machine tools, equipment's and other items are not clean. & & & & & & \\
\hline & & 15. & Sanitary items are not easily assessable. & & & & & & \\
\hline & & 16. & Signage and board are either dirty or broken. & & & & & & \\
\hline & & 17. & Relevant issues & & & & & & \\
\hline \multirow{5}{*}{ D } & & 18. & Implementation of the first $3 \mathrm{~S}$ & & & & & & \\
\hline & $\begin{array}{l}\text { STANDARDIZE } \\
\text { (NORMALIZE) }\end{array}$ & 19. & Standards are not properly documented & & & & & & \\
\hline & חיח & 20. & Job, cleaning, and another checklist not framed & & & & & & \\
\hline & & 21. & Part recognition is poor & & & & & & \\
\hline & & 22. & Items located in specified limit & & & & & & \\
\hline \multirow{5}{*}{$\mathbf{E}$} & \multirow{5}{*}{$\begin{array}{l}\text { SHITSUK } \\
\text { DISCIPLINE } \\
\text { (SUSTAIN) }\end{array}$} & 23. & Adhere with rules & & & & & & \\
\hline & & 24. & Workers not undergone $5 S$ training & & & & & & \\
\hline & & 25. & The frequency for not performing $5 S$ in last week & & & & & & \\
\hline & & 26. & How many jobs not updated as per standard & & & & & & \\
\hline & & 27. & $\begin{array}{l}\text { The frequency for last week that belongings not } \\
\text { properly maintained }\end{array}$ & & & & & & \\
\hline
\end{tabular}

\subsubsection{Autonomous Maintenance}

This maintenance is the first pillar of total productive maintenance strategy. As industry mostly suffers from either planned downtime or unplanned downtime, each time needs to be reduced through applying effective strategies and methodologies in the industry. This methodology helps the industry to lessen downtime due to common causes. In this strategy, the operator endlessly monitors their machines and performs minor tasks, adjustment, and set up on the machine by own effort without assigning to, specifically, maintenance personnel. This saves a lot of wastages in form of either waiting, transportation, motion, or non-availability of the specialized worker. Technical knowledge about machine and workplace imparts to workers a feeling of ownership for the whole workplace so that they can standardize routine inspection schedule. The effective autonomous maintenance works on two principal elements: (1) the proper operation helps in less depreciation of machine, and (2) keeping equipment in "like new" situation 
through effective repair and management. The autonomous procedure is demonstrated in Figure 12.

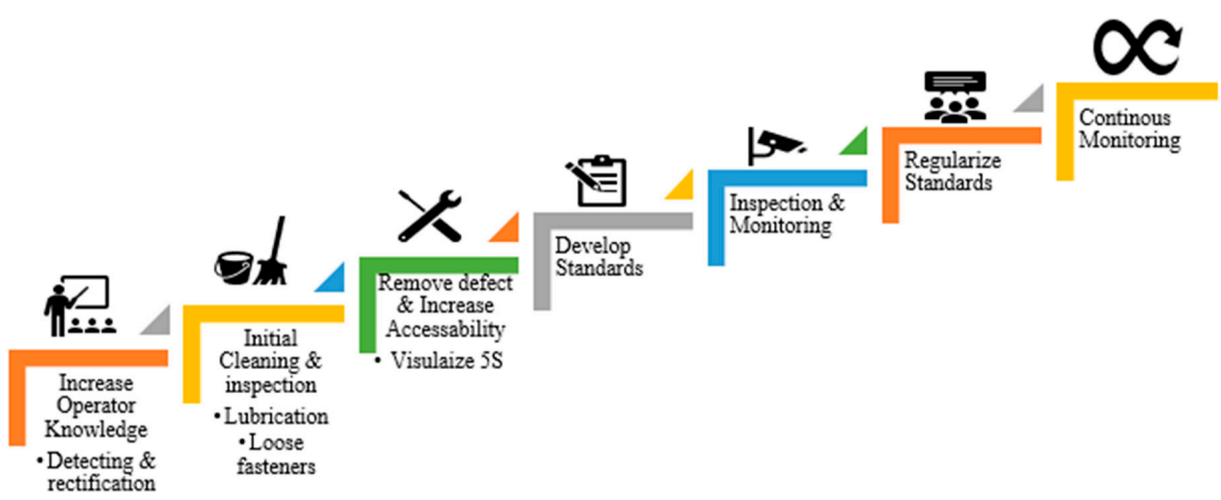

Figure 12. Autonomous maintenance procedure.

\subsection{Improved OEE}

Figure 3 reveals that the overall equipment effectiveness of the machine was $68.6 \%$. There were a lot of scopes to increase this OEE for the improvement of the industry. Efforts were made through the implementation of an effective strategy in the industry. Six big losses adversely affect the effectiveness of industry, and these losses were thoroughly attempted with the help of 1st, 2nd, and 3rd Pareto analysis and FBD. The major causes like tooling failure, unplanned maintenance, process parameter, and improper training were thoroughly analyzed and effectively communicated with the production and management teams. The improved data were apprehended and improved OEE was calculated as listed in Table 4.

Table 4. Improved key metrics.

\begin{tabular}{|c|c|c|c|c|c|}
\hline No. & Key Terms & Symbol & Past Value & Present Value & Unit \\
\hline 1. & Plant Operating Time & $\mathrm{P}_{\mathrm{O}}$ & $1 \times 8$ hrs. $=8$ hrs $=480$ & $1 \times 8$ hrs. $=8$ hrs $=480$ & $\min$ \\
\hline 2. & Planned Shutdown Time & $\mathrm{P}_{\mathrm{S}}$ & $\begin{array}{c}2 \text { Short Breaks @10 } \min =20 \\
1 \text { Meal Break @ } 30 \mathrm{~min}=30 \\
\text { Total = 50 }\end{array}$ & $\begin{array}{c}2 \text { Short Breaks @10 } \min =20 \\
1 \text { Meal Break @ } 30 \mathrm{~min}=30 \\
\text { Total = 50 }\end{array}$ & $\min$ \\
\hline 3. & Planned Production Time & $\mathrm{P}_{\mathrm{T}}$ & $480-50=430$ & $480-50=430$ & $\min$ \\
\hline 4. & Down Time & $\mathrm{D}_{\mathrm{T}}$ & 40 & 20 & $\min$ \\
\hline 5. & Operative Time & $\mathrm{O}_{\mathrm{T}}$ & $430-40=390$ & $430-20=410$ & $\min$ \\
\hline 6. & Ideal Cycle Time & $\mathrm{C}_{\mathrm{T}}$ & 1 & 1 & $\min$ \\
\hline 7. & Total no. of Pieces & $\mathrm{N}$ & 330 & 380 & count \\
\hline 8. & Minor Stoppages & M & 30 & 15 & $\min$ \\
\hline 9. & Net Operating Time & $\mathrm{N}_{\mathrm{T}}$ & $390-30=360$ & $410-15=395$ & $\min$ \\
\hline 10. & Efficient Net Operating Time & $\mathrm{E}_{\mathrm{T}}$ & $1 \times 330=330$ & $1 \times 380=380$ & $\min$ \\
\hline 11. & Rejected Pieces & $\mathrm{N}_{\mathrm{R}}$ & 35 & 15 & count \\
\hline 12. & Good Unit & G & $330-35=295$ & $380-15=365$ & count \\
\hline 13. & Availability & A & $390 / 430=90.70$ & $410 / 430=95.30$ & $\%$ \\
\hline 14. & Performance & $\mathrm{P}$ & $\frac{[1 \times 330]}{390}=84.62$ & $\frac{[1 \times 380]}{410}=92.68$ & $\%$ \\
\hline 15. & Quality & $\mathrm{Q}$ & $295 / 330=89.39$ & $365 / 380=96.05$ & $\%$ \\
\hline 16. & Overall Equipment Efficiency & OEE & $90.70 \times 84.62 \times 89.39=68.60$ & $95.30 \times 92.68 \times 96.05=84.83$ & $\%$ \\
\hline 17. & Asset Utilization & AU & $390 / 480=81.25$ & $410 / 480=85.41$ & $\%$ \\
\hline
\end{tabular}




\section{Conclusions}

The healthy strategies in the industry help to sustain effectiveness for qualitative and quantitative production, which leads to higher customer satisfaction. To ensure this, researchers proposed a novel approach in this study for increasing the effectiveness in the industry. There are seven major losses present in the industry which adversely affects the effectiveness of machine in any industry. This approach can reduce these losses and improve the quality, asset utilization (AU), OEE, total effective equipment performance (TEEP), and productivity of the machine. The study exposes that Pareto analysis uncovers all the losses and works on the principle of $80 / 20$ rule. The major losses were thoroughly explored with the help of the fishbone diagram and solutions were implemented on the shop floor.

In the current paper, the OEE approach jointly with Pareto analysis and fishbone diagram accords superior control over the production efficiency. Planned downtime, reject/rework, minor stoppage, and speed loss considered main causes through Pareto analysis as presented in Figure 4. The losses reject/rework, minor stoppage, speed loss, unplanned downtime, and setup downtime decreased as demonstrated by Figure 13 . Performance key metrics were remarkably improved (refer to Figure 14). In other word, key metrics i.e., availability, performance, quality, OEE, asset utilization, and total effective equipment performance showed improvements by $4.6 \%, 8.06 \%, 6.66 \%, 16.23 \%, 4.16 \%$, and $14.58 \%$, respectively, after successful execution of trilogy approach in the industry. The statistical tool, condition monitoring, and other management tools can be used to mitigate the losses. In summary, the approach offers a good opportunity for both researchers and small-medium enterprises around the world to analyze the indicators of production losses, performance, and productivity in the manufacturing industry. Research efforts proposed in the future include further development of existing assessment methods, conducting hybrid analysis by collaborating with different methods, and investigating more determining factors affecting key metrics in the manufacturing industry.

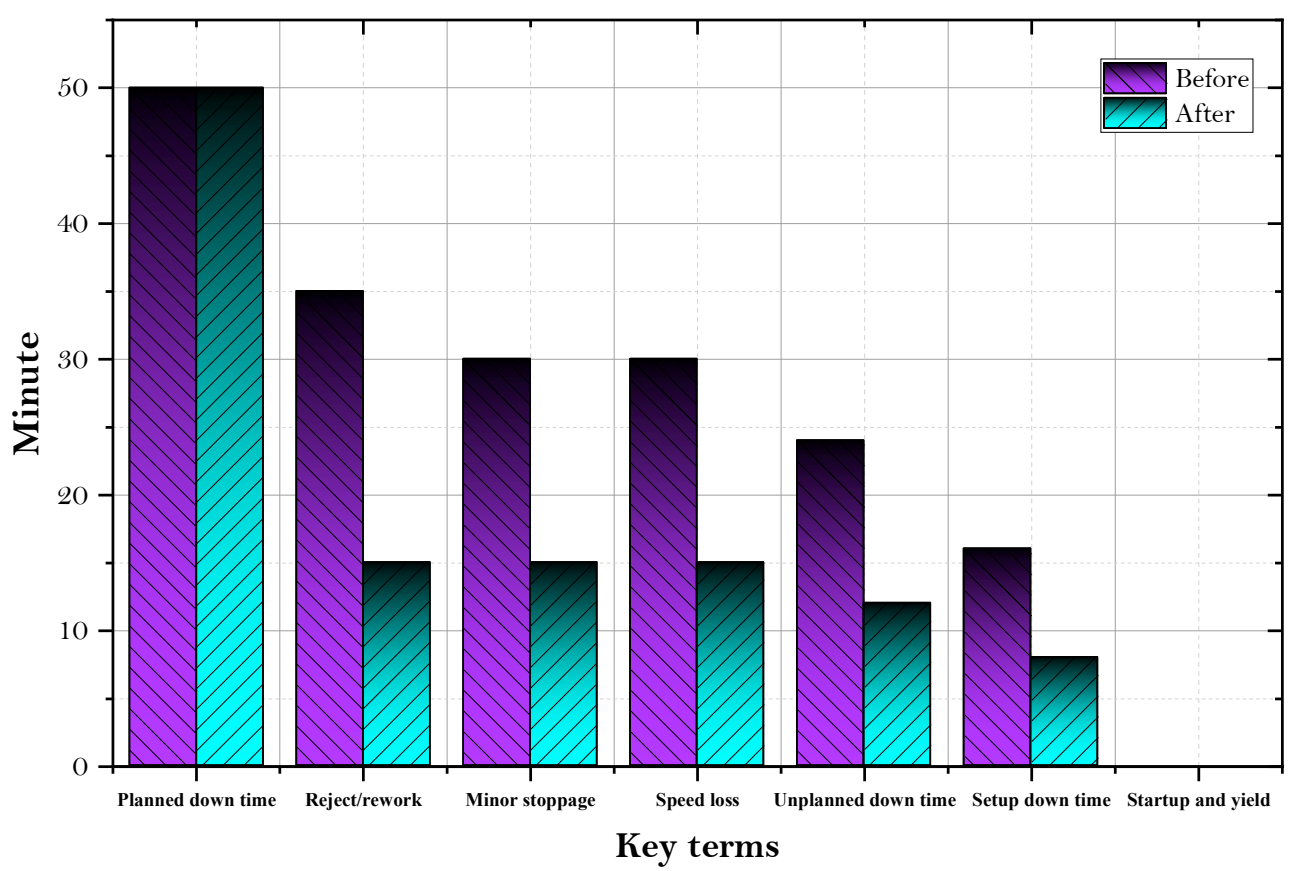

Figure 13. Comparison of seven big losses. 


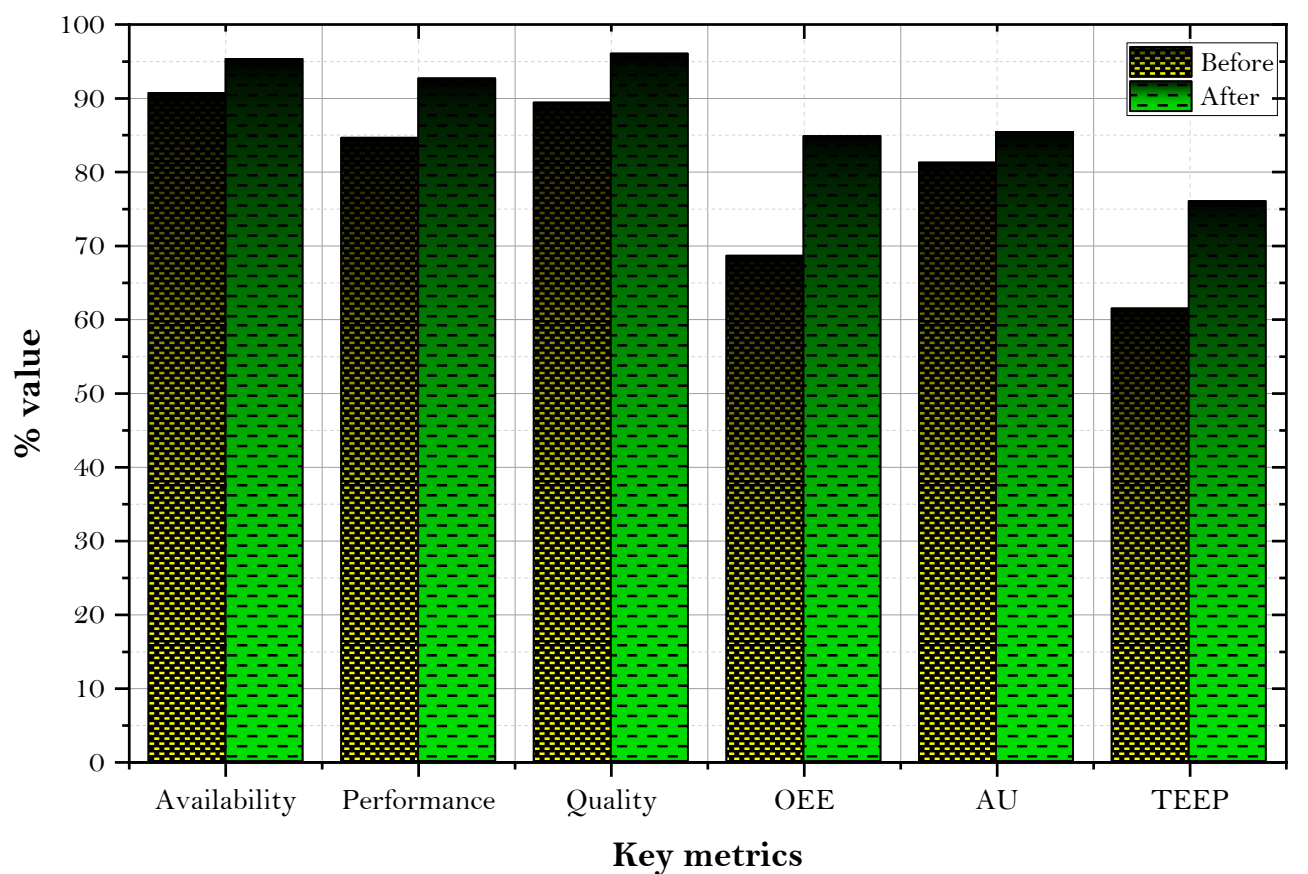

Figure 14. Comparison of key metrics.

Author Contributions: Conceptualization, A.T., N.S.K., and M.K.G.; methodology, A.T. and M.K.G.; software, M.K.G. and M.S.; validation, M.K.G., D.Y.P., and N.S.K.; formal analysis, A.T. and M.K.G.; investigation, A.T.; resources, M.K.G. and D.Y.P.; data curation, A.T. and N.S.K.; writing-original draft preparation, A.T.; writing—review and editing, A.T. and C.I.P.; visualization, M.S. and M.K.G.; supervision, N.S.K.; project administration, N.S.K. All authors have read and agreed to the published version of the manuscript.

Funding: This research received no external funding.

Data Availability Statement: The data presented in this study are openly available online.

Conflicts of Interest: The authors declare no conflict of interest.

\section{References}

1. Franco, M.; Haase, H. Interfirm Partnerships and Organizational Innovation: Study of SMEs in the Automotive Sector. J. Open Innov. Technol. Mark. Complex. 2020, 6, 193. [CrossRef]

2. Rocco, C.M.; Hernandez-Perdomo, E.; Mun, J. Introduction to Formal Concept Analysis and Its Applications in Reliability Engineering. Reliab. Eng. Syst. Saf. 2020, 107002. [CrossRef]

3. Freiheit, T.; Hu, S.J. Impact of Machining Parameters on Machine Reliability and System Productivity. J. Manuf. Sci. Eng. 2002, 124, 296-304. [CrossRef]

4. Supattananon, N.; Akararungruangkul, R. Modified Differential Evolution Algorithm for a Transportation Software Application. J. Open Innov. Technol. Mark. Complex. 2019, 5, 84. [CrossRef]

5. Sooraj, S.; Vijayakumar, N.; Gaitonde, V.N.; Kotturshettar, B.B. Productivity Improvement of a Manufacturing Industry by Process Improvement through Bottleneck and Root Cause Analysis. In AIP Conference Proceedings; AIP Publishing LLC: Melville, NY, USA, 2019; Volume 2200, p. 20053.

6. Basu, P.; Nath, A. Productivity Improvement by Root Cause Analysis in Manufacturing Industry. Int. J. Sci. Res. Dev. 2016, 4, 36-42.

7. Jirasirilerd, G.; Pitakaso, R.; Sethanan, K.; Kaewman, S.; Sirirak, W.; Kosacka-Olejnik, M. Simple Assembly Line Balancing Problem Type 2 by Variable Neighborhood Strategy Adaptive Search: A Case Study Garment Industry. J. Open Innov. Technol. Mark. Complex. 2020, 6, 21. [CrossRef]

8. Purba, H.H.; Wijayanto, E.; Aristiara, N. Analysis of Overall Equipment Effectiveness (OEE) with Total Productive Maintenance Method on Jig Cutting: A Case Study in Manufacturing Industry. J. Sci. Eng. Res. 2018, 5, 397-406.

9. Chong, K.E.; Ng, K.C.; Goh, G.G.G. Improving Overall Equipment Effectiveness (OEE) through Integration of Maintenance Failure Mode and Effect Analysis (Maintenance-FMEA) in a Semiconductor Manufacturer: A Case Study. IEEE Int. Conf. Ind. Eng. Eng. Manag. 2016, 1427-1431. [CrossRef] 
10. Kapuria, T.K.; Rahman, M.; Haldar, S. Root Cause Analysis and Productivity Improvement of An Apparel Industry in Bangladesh Through Kaizen Implementation. J. Appl. Res. Ind. Eng. 2017, 4, 227-239. [CrossRef]

11. Nallusamy, S. Enhancement of Productivity and Efficiency of CNC Machines in a Small Scale Industry Using Total Productive Maintenance. Int. J. Eng. Res. Africa 2016, 25, 119-126. [CrossRef]

12. Nallusamy, S.; Muthamizhmaran, S. Enhancement of Productivity and Overall Equipment Efficiency Using Time and Motion Study Technique-A Review. Adv. Eng. Forum 2015, 14, 59-66. [CrossRef]

13. Low, S.-N.; Chong, S.-H.; Sim, H.-Y.; Razalli, S.; Kamaruddin, S. Measurement of Overall Performance Effectiveness in Setup Improvement. J. Ind. Eng. 2014, 2014, 264980. [CrossRef]

14. Garza-Reyes, J.A. From Measuring Overall Equipment Effectiveness (OEE) to Overall Resource Effectiveness (ORE). J. Qual. Maint. Eng. 2015, 21, 506-527. [CrossRef]

15. Hedman, R.; Subramaniyan, M.; Almström, P. Analysis of Critical Factors for Automatic Measurement of OEE. Procedia CIRP 2016, 57, 128-133. [CrossRef]

16. Azizi, A. Evaluation Improvement of Production Productivity Performance Using Statistical Process Control, Overall Equipment Efficiency, and Autonomous Maintenance. Procedia Manuf. 2015, 2, 186-190. [CrossRef]

17. Puvanasvaran, A.P.; Mei, C.Z.; Alagendran, V.A. Overall Equipment Efficiency Improvement Using Time Study in an Aerospace Industry. Procedia Eng. 2013, 68, 271-277. [CrossRef]

18. Puvanasvaran, A.P.; Yoong, S.S.; Tay, C.C. Effect of Hidden Wastes in Overall Equipment Effectiveness Calculation. ARPN J. Eng. Appl. Sci. 2017, 12, 6443-6448.

19. Wolniak, R. Downtime in the Automotive Industry Production Process-Cause Analysis. Qual. Innov. Prosper. 2019, 23, 101-118. [CrossRef]

20. Wan, S.; Li, D.; Gao, J.; Roy, R.; He, F. A Collaborative Machine Tool Maintenance Planning System Based on Content Management Technologies. Int. J. Adv. Manuf. Technol. 2018, 94, 1639-1653. [CrossRef]

21. Salonitis, K.; Kolios, A. Reliability Assessment of Cutting Tool Life Based on Surrogate Approximation Methods. Int. J. Adv. Manuf. Technol. 2014, 71, 1197-1208. [CrossRef]

22. Yun, J.J.; Kim, D.; Yan, M.-R. Open Innovation Engineering-Preliminary Study on New Entrance of Technology to Market. Electronics 2020, 9, 791. [CrossRef]

23. Yun, J.J.; Zhao, X.; Park, K.; Shi, L. Sustainability Condition of Open Innovation: Dynamic Growth of Alibaba from SME to Large Enterprise. Sustainability 2020, 12, 4379. [CrossRef]

24. Yun, J.J.; Zhao, X.; Jung, K.; Yigitcanlar, T. The Culture for Open Innovation Dynamics. Sustainability 2020, 12, 5076. [CrossRef]

25. Munir, H.; Linåker, J.; Wnuk, K.; Runeson, P.; Regnell, B. Open Innovation Using Open Source Tools: A Case Study at Sony Mobile. Empir. Softw. Eng. 2018, 23, 186-223. [CrossRef]

26. Enkel, E.; Gassmann, O.; Chesbrough, H. Open R\&D and Open Innovation: Exploring the Phenomenon. R D Manag. 2009, 39, 311-316. [CrossRef]

27. Sonmez, V.; Testik, M.C.; Testik, O.M. Overall Equipment Effectiveness When Production Speeds and Stoppage Durations Are Uncertain. Int. J. Adv. Manuf. Technol. 2018, 95, 121-130. [CrossRef]

28. Chikwendu, O.C.; Chima, A.S.; Edith, M.C. The Optimization of Overall Equipment Effectiveness Factors in a Pharmaceutical Company. Heliyon 2020, 6, e03796. [CrossRef] [PubMed]

29. Yazdani, A.-A.; Tavakkoli-Moghaddam, R. Integration of the Fish Bone Diagram, Brainstorming, and AHP Method for Problem Solving and Decision Making—a Case Study. Int. J. Adv. Manuf. Technol. 2012, 63, 651-657. [CrossRef]

30. Gupta, M.K.; Sood, P.K.; Singh, G.; Sharma, V.S. Sustainable Machining of Aerospace Material-Ti (Grade-2) Alloy: Modeling and Optimization. J. Clean. Prod. 2017, 147, 614-627. [CrossRef]

31. Gupta, M.K.; Sood, P. Machining Comparison of Aerospace Materials Considering Minimum Quantity Cutting Fluid: A Clean and Green Approach. Proc. Inst. Mech. Eng. Part C J. Mech. Eng. Sci. 2017, 231, 1445-1464. [CrossRef]

32. Singh, G.; Pruncu, C.I.; Gupta, M.K.; Mia, M.; Khan, A.M.; Jamil, M.; Pimenov, D.Y.; Sen, B.; Sharma, V.S. Investigations of Machining Characteristics in the Upgraded MQL-Assisted Turning of Pure Titanium Alloys Using Evolutionary Algorithms. Materials 2019, 12, 999. [CrossRef] [PubMed]

33. Gupta, M.K.; Song, Q.; Liu, Z.; Pruncu, C.I.; Mia, M.; Singh, G.; Lozano, J.A.; Carou, D.; Khan, A.M.; Jamil, M.; et al. Machining Characteristics Based Life Cycle Assessment in Eco-Benign Turning of Pure Titanium Alloy. J. Clean. Prod. 2020, $251,119598$. [CrossRef]

34. Gupta, M.K.; Mia, M.; Pruncu, C.I.; Kapłonek, W.; Nadolny, K.; Patra, K.; Mikolajczyk, T.; Pimenov, D.Y.; Sarikaya, M.; Sharma, V.S. Parametric Optimization and Process Capability Analysis for Machining of Nickel-Based Superalloy. Int. J. Adv. Manuf. Technol. 2019, 102, 3995-4009. [CrossRef]

35. Sarıkaya, M.; Yılmaz, V.; Dilipak, H. Modeling and Multi-Response Optimization of Milling Characteristics Based on Taguchi and Gray Relational Analysis. Proc. Inst. Mech. Eng. Part B J. Eng. Manuf. 2016, 230, 1049-1065. [CrossRef]

36. Gupta, M.K.; Mia, M.; Jamil, M.; Singh, R.; Singla, A.K.; Song, Q.; Liu, Z.; Khan, A.M.; Rahman, M.A.; Sarikaya, M. Machinability Investigations of Hardened Steel with Biodegradable Oil-Based MQL Spray System. Int. J. Adv. Manuf. Technol. 2020, 108, 735-748. [CrossRef]

37. Gupta, M.K.; Mia, M.; Singh, G.R.; Pimenov, D.Y.; Sarikaya, M.; Sharma, V.S. Hybrid Cooling-Lubrication Strategies to Improve Surface Topography and Tool Wear in Sustainable Turning of Al 7075-T6 Alloy. Int. J. Adv. Manuf. Technol. 2019. [CrossRef] 
38. Grzesik, W. Chapter Fourteen-Machining Economics and Optimization. In Advanced Machining Processes of Metallic Materials, 2nd ed.; Elsevier: Amsterdam, The Netherlands, 2017; pp. 265-283.

39. Khan, A.M.; Jamil, M.; Mia, M.; He, N.; Zhao, W.; Gong, L. Sustainability-Based Performance Evaluation of Hybrid Nanofluid Assisted Machining: Sustainability Assessment of Hybrid Nanofluid Assisted Machining. J. Clean. Prod. 2020, $257,120541$. [CrossRef]

40. Khan, A.M.; Gupta, M.K.; Hegab, H.; Jamil, M.; Mia, M.; He, N.; Song, Q.; Liu, Z.; Pruncu, C.I. Energy-Based Cost Integrated Modelling and Sustainability Assessment of Al-GnP Hybrid Nanofluid Assisted Turning of AISI52100 Steel. J. Clean. Prod. 2020, 257, 120502. [CrossRef]

41. Yıldırım, Ç.V.; Kıvak, T.; Sarıkaya, M.; Erzincanlı, F. Determination of MQL Parameters Contributing to Sustainable Machining in the Milling of Nickel-Base Superalloy Waspaloy. Arab. J. Sci. Eng. 2017, 42, 4667-4681. [CrossRef]

42. Sarikaya, M.; Güllü, A. Taguchi Design and Response Surface Methodology Based Analysis of Machining Parameters in CNC Turning under MQL. J. Clean. Prod. 2014, 65, 604-616. [CrossRef]

43. Sarıkaya, M.; Güllü, A. Multi-Response Optimization of Minimum Quantity Lubrication Parameters Using Taguchi-Based Grey Relational Analysis in Turning of Difficult-to-Cut Alloy Haynes 25. J. Clean. Prod. 2015, 91, 347-357. [CrossRef] 